\section{BMJ Global Health} Pougué Biyong $\mathrm{C}$, et al. The relatively young and rural population may limit the spread and severity of COVID-19 in Africa: a modelling study. BMJ Global Health 2020;5:e002699. doi:10.1136/ bmjgh-2020-002699

Handling editor Seye Abimbola

- Additional material is published online only. To view please visit the journal online (http://dx.doi.org/10.1136/ bmjgh-2020-002699).

Received 4 May 2020

Revised 4 May 2020

Accepted 5 May 2020

\section{Check for updates}

(c) Author(s) (or their employer(s)) 2020. Re-use permitted under CC BY-NC. No commercial re-use. See rights and permissions. Published by BMJ.

${ }^{1}$ Economics, University of Oxford, Oxford, UK ${ }^{2}$ Mathematics and Computer Science, Argonne National Laboratory, Lemont, Illinois, USA ${ }^{3}$ Economics, Université Paris 1 Panthéon-Sorbonne, Paris, Îlede-France, France

${ }^{4}$ Mathematics, University of Oxford, Oxford, UK

Correspondence to Ms Binta Zahra Diop; bintazahra.diop@economics. ox.ac.uk

\title{
The relatively young and rural population may limit the spread and severity of COVID-19 in Africa: a modelling study
}

\author{
Binta Zahra Diop (D , ${ }^{1}$ Marieme Ngom, ${ }^{2}$ Clémence Pougué Biyong, ${ }^{3}$ \\ John N Pougué Biyong ${ }^{4}$
}

\section{ABSTRACT \\ Introduction A novel coronavirus disease 2019}

(COVID-19) has spread to all regions of the world. There is great uncertainty regarding how countries' characteristics will affect the spread of the epidemic; to date, there are few studies that attempt to predict the spread of the epidemic in African countries. In this paper, we investigate the role of demographic patterns, urbanisation and comorbidities on the possible trajectories of COVID-19 in Ghana, Kenya and Senegal.

Methods We use an augmented deterministic Susceptible-Infected-Recovered model to predict the true spread of the disease, under the containment measures taken so far. We disaggregate the infected compartment into asymptomatic, mildly symptomatic and severely symptomatic to match observed clinical development of COVID-19. We also account for age structures, urbanisation and comorbidities (HIV, tuberculosis, anaemia).

Results In our baseline model, we project that the peak of active cases will occur in July, subject to the effectiveness of policy measures. When accounting for the urbanisation, and factoring in comorbidities, the peak may occur between 2 June and 17 June (Ghana), 22 July and 29 August (Kenya) and, finally, 28 May and 15 June (Senegal). Successful containment policies could lead to lower rates of severe infections. While most cases will be mild, we project in the absence of policies further containing the spread, that between $0.78 \%$ and $1.03 \%, 0.61 \%$ and $1.22 \%$, and $0.60 \%$ and $0.84 \%$ of individuals in Ghana, Kenya and Senegal, respectively, may develop severe symptoms at the time of the peak of the epidemic. Conclusion Compared with Europe, Africa's younger and rural population may modify the severity of the epidemic. The large youth population may lead to more infections but most of these infections will be asymptomatic or mild, and will probably go undetected. The higher prevalence of underlying conditions must be considered.

\section{INTRODUCTION}

Since the first reported severe acute respiratory syndrome coronavirus 2 (SARS-CoV-2) infection in December 2019, the virus has spread to all continents. ${ }^{1}$ There is still little

\section{Key questions}

What is already known?

- While most COVID-19 studies focus on western and Asian countries, very few are concerned with the spread of the virus in African countries.

- Most African countries have relatively low urbanisation rates, a young population and context-specific comorbidities that are still to be explored in the spread of COVID-19.

What are the new findings?

- In our baseline predictions $33 \%-50 \%$ of the public will be actively infected at the peak of the epidemic and 1 in 36 (Ghana), 1 in 40 (Kenya) and 1 in 42 (Senegal) of these active cases may be severe.

- With rural areas, infection may be lowered to $65 \%$ $73 \%$ (Ghana), 48\%-71\% (Kenya) and 61\%-69\% (Senegal) of the baseline infections.

- Comorbidities may however increase the ratio of severe infections among the active cases at the peak of the epidemic.

What do the new findings imply?

- Rural areas and large youth population may limit the spread and severity of the epidemic and outweigh the negative impact of HIV, tuberculosis and anaemia.

evidence on the pattern of the spread in Africa. Although the African continent is made up of countries with different infrastructures, health policies and characteristics in the face of this novel coronavirus disease 2019 (COVID-19), some characteristics such as a young population, ${ }^{2}$ comorbidities (tuberculosis (TB), HIV, anaemia ${ }^{34}$ ) and low urbanisation rates transcend these differences and have been seldom considered in the large number of studies published to date. For example, the median age below $20,{ }^{5}$ and the low rates of urbanisation, could potentially 
lead to a lower death toll of the epidemic in African countries than elsewhere.

However, having a young population implies that many infected individuals may not display symptoms and will risk infecting more people than would symptomatic individuals. ${ }^{6}$ Additionally, the large number of informal settlements could accentuate this phenomenon. It is therefore urgent to develop a framework that could accurately predict the spread of the virus, accounting for the idiosyncrasies of the African context. A country-specific model will provide policymakers with a wide range of prediction scenarios, based on different actions they can take to address the pandemic. With the scarce resources at their disposal, ${ }^{78}$ models like these will help target prevention strategies to individuals with comorbidities who might suffer the most from the epidemic. Moreover, with containment policies that can grind economies to a halt, ${ }^{9}$ understanding the trade-off between rural and urban spreads could lead to better informed decisions between the short-term impacts of the epidemic, and the long-term looming shortage in the food supply that could stem enforcing strict social distancing measures in rural areas.

This study contributes to the meagre literature on the burden of the virus on African countries; it also adds to the use of differential equation models to predict the spread of epidemics. This paper focuses on three African countries that have received little attention: Ghana, Kenya and Senegal. We chose Kenya to have a comparison point with another in-depth study by Brand $e t a l .{ }^{10}$ Ghana and Senegal, on the other hand, have had transparent data sharing policies from the start of the epidemic; they made available publicly the number of positive cases, the number tests conducted and a clear outline of the containment measures. Ghana has an extensive testing policy, while Senegal has tested very few individuals comparatively (As of 1 May 2020, Ghana has conducted 3.37 tests per thousand individuals while Kenya and Senegal are respectively at 0.4 and $0.76^{11}$ ), we are thus able to see the difference in predictions for two countries that have adopted widely different testing strategies.

To project the trends of the epidemic, we augment the canonical Susceptible-Infected-Recovered (SIR) by splitting the infected compartment into three groups: an infected without symptoms, an infected with mild symptoms and, finally, the infected with severe symptoms. With our projections accounting for policies implemented to date, we present different scenarios accounting for local policies, urbanisation and comorbidities. Our strategy is relevant beyond the application of this paper; it could be used in Asian or European contexts as well, and is similar to work by Ferguson $e t a l^{12}$ who discuss suppression and mitigation measures in the UK and the USA.

\section{METHODS}

\section{Compartmental epidemiological model}

Several models have been used to predict the spread of the virus. Read et al ${ }^{13}$ use a standard Susceptible-Exposed-InfectedRecovered (SEIR) model with an exposed compartment that comprises infected individuals who do not yet have symptoms and who are not infectious. Danon $e t \mathrm{al}^{14}$ also use a SEIR model but split the infected compartment into two subcompartments: mild symptoms and symptomatic. Finally, Arenas et al $\mathrm{s}^{15}$ study uses a model composed of susceptible, exposed, asymptomatic infectious, infected, hospitalised to intensive care unit (ICU), dead and recovered compartments; however, they assume that all asymptomatic infectious individuals cannot recover before they ever develop symptoms.

There is early evidence that a large number of individuals infected with COVID-19 will recover without ever developing symptoms and that asymptomatic individuals are contagious to varying degrees. ${ }^{16-19}$ Based on these findings, our model assumes that individuals are contagious from the moment they get infected. We define an SIR model with vital dynamics (see online supplementary appendix figure 1). The known natural progression of the disease is (1) asymptomatic, (2) mild symptomatic, (3) moderate symptomatic, (4) severe, and (5) critical. There are benefits in understanding the heterogeneity among infected individuals, namely those carriers without symptoms (asymptomatic), carriers with symptoms (mild and moderately symptomatic) and severe cases who might seek medical attention (severe and critical). We therefore propose to divide the infected compartment into three subcompartments: asymptomatic infectious, mildly (and moderate) symptomatic infectious, and severely (and critically) infected requiring medical attention.

We introduce some notations. $S$ is the share of susceptible, that is, individuals who are exposed to the virus but not immune. $I_{a s}, I_{m s}$ and $I_{s s}$ are respectively the shares of asymptomatic, mildly symptomatic and severely symptomatic individuals. $R$ is the share of immune individuals. $D$ is the share of deceased individuals (due to COVID-19 and other non-related causes). All numbers are expressed in terms of percentages of the total population. We note $I=I_{a s}+I_{m s}+I_{s s}$ the total share of infected and $N=S+I+R$ the share of individuals alive. We suppose that borders are closed. Moreover, all compartments experience natural vital dynamics via the birth rate $\mu_{\text {birt }}$ and the death rate $\mu_{\text {death }}$ from causes unrelated to the virus (eg, long-term diseases, accidents). Daily epidemic transmission is described by equations (1)-(5):

$$
\frac{d S}{d t}=-\beta S I+\mu_{\text {bith }}(S+R)-\mu_{\text {death }} S
$$

where $\beta S I=\beta_{a s} S I_{a s}+\beta_{m s} S I_{m s}+\beta_{s s} S I_{s s}$.

$\beta_{a s}$ is the contact rate between asymptomatic infected individuals and susceptible ones. Because asymptomatic individuals are not aware of their infection, their rate of contact with susceptible individuals is the same as the rate of contact within the group of susceptible individuals. This contact rate will vary with containment measures that are enforced within each country.

$\beta_{m s}$ is the contact rate between mildly symptomatic individuals and susceptible ones. It is assumed to be lower than $\beta_{a s}$ because symptomatic individuals tend to selfisolate, either because they are bedridden due to their 
symptoms or simply because they want to limit contacts with susceptible individuals.

$\beta_{s s}$ is the contact rate between severely symptomatic and susceptible individuals. Individuals who experience severe symptoms may seek medical care and get admitted as inpatients at a hospital. They might not get hospital care for various reasons (eg, health facilities are overwhelmed). This rate accounts for contacts between hospitalised patients and healthcare workers, but can also be interpreted as contacts between severely symptomatic individuals and any caregiver (at home for instance, if the health services are overloaded). It also accounts for the contacts between hospitalised severely symptomatic individuals and susceptible individuals outside of their caretakers. It remains unclear how contacts other than healthcare workers affect the value of $\beta_{s s}$.

$$
\frac{d I_{a s}}{d t}=\beta S I-\frac{r_{a s}}{T_{\text {rec }, a s}} I_{a s}-\frac{\left(1-r_{a s}\right)}{T_{\text {inc }}} I_{a s}-\mu_{\text {death }} I_{a s}
$$

where $r_{a s}$ is the probability of recovery without ever developing symptoms, $T_{\text {recas }}$ is the recovery time of an asymptomatic individual and $T_{i n c}$ is the incubation period during which an individual is infected and infectious, but does not have symptoms. We define the asymptomatic effective reproduction number as the average number of secondary cases per asymptomatic case at time $t$.

$$
\begin{aligned}
& \frac{d I_{m s}}{d t}=\frac{\left(1-r_{a s}\right)}{T_{\text {inc }}} I_{a s}-\frac{d_{m s}}{T_{d}} I_{m s}-\left(1-d_{m s}\right)\left(\frac{r_{m s}}{T_{r e c}, m s}+\frac{1-r_{m s}}{T_{s e v}}\right) \\
& I_{m s}-\mu_{\text {death } h} I_{m s}
\end{aligned}
$$

where $d_{m s}$ is the probability of dying from a fast deterioration, $T_{d}$ is the time elapsed between the appearance of first symptoms and the death of the individual, $r_{m s}$ is the probability to recover from mild symptoms, $T_{\text {rec } m s}$ is the recovery time associated with $r_{m s}$ and $T_{s e v}$ is the time for severe symptoms to develop. We deviate for the recovery rates of the mildly symptomatic compartment $r_{m s}$ by taking the weighted average of age-grouped fatality rates of COVID-19 found in Hubei, Hong Kong and Macau ${ }^{20}$ :

$$
r_{m s}=\sum_{a g} w_{a g}\left(1-f_{a g}\right)
$$

where the sum is over the age groups $a g \in\{[0,9],[10$, $19], \ldots,[70,79], 80+\}, w_{a g}$ is the share of the population in age group $a g$ and $f_{a g}$ is the fatality rate found in earlier studies for the population in age group. ${ }^{18}$

$$
\frac{d I_{s s}}{d t}=\frac{\left(1-r_{m s}\right)\left(1-d_{m s}\right)}{T_{s e v}} I_{m s}-\frac{d_{s s}}{\alpha T_{d}} I_{s s}-\frac{\left(1-d_{s s}\right)}{T_{r e c, s s}} I_{s s}-\mu_{\text {death }} I_{s s}
$$

where $d_{s s}$ is the probability of dying after progressively developing severe symptoms that require hospitalisation, $T_{r e c, s s}$ is the recovery time of the severely symptomatic. $\alpha T_{d}$ is the time to death from the start of severe symptoms, for individuals who pass away from severe, progressively developing symptoms. Intuitively, if most severe cases are hospitalised, $\alpha$ should be higher than 1 as health professionals will slow down the evolution of the disease.

$$
\frac{d R}{d t}=\frac{r_{a s}}{T_{\text {rec }, a s}} I_{a s}+\left(1-d_{m s}\right) \frac{r_{m s}}{T_{r e c, m s}} I_{m s}+\frac{\left(1-d_{s s}\right)}{T_{\text {rec }, s s}} I_{s s}-\mu_{\text {death }} R
$$

$$
\frac{d D}{d t}=\mu_{\text {death }} N+\frac{d_{m s}}{T_{d}} I_{m s}+\frac{d_{s s}}{\alpha T_{d}} I_{s s}
$$

In our simulations, we include fatalities, but we do not include the outcomes in the results. We make this choice because of the high uncertainty around the capacity of the healthcare systems of each individual country to absorb the increased demand from patients who are severely ill. For instance, with the same predictions, a country that has a stock of ventilators of 1000 will likely have less fatalities than a country with no ventilators. Because we do not have data on healthcare capacities, we chose not to present these results. Our predicted number of fatalities is however subtracted from the number of susceptibles.

\section{Patient and public involvement}

Our study does not involve the participation of patients or any members of the public. All data used for the purpose of this study are aggregated and publicly available.

\section{RESULTS}

\section{Baseline simulations}

We use publicly available data from the European Centre for Disease Prevention and Control, and from daily press releases made by the Senegalese Ministry of Health and Social Protection. ${ }^{21}{ }^{22}$ We also do checks using the Ghana Health Service and the Kenya Ministry of Health websites.

Whenever possible, we use values of parameters drawn from the literature to fit the model (see table 1).

Although there are reports that as many as $80 \%$ of active cases are asymptomatic, ${ }^{23}$ these reports are based on cases that are still active and include presymptomatic individuals. We thus use $40 \%$ as the share of individuals infected with COVID-19 who recover without ever developing symptoms. ${ }^{16-19}$

Ghana, Kenya and Senegal have extensive communication strategies including in local languages to ensure that communities are able to detect the symptoms of COVID-19 such as a cough and fever and would report any person with those symptoms. We therefore use the share of individuals who do not have a cough as a proxy for the rate of symptomatic infected individuals who can leave their home without being reported. Wang et $a l^{24}$ find that $59 \%$ of individuals who test positive for COVID-19 have a cough which implies $\beta_{m s}=0.41 \beta_{a s}$. We

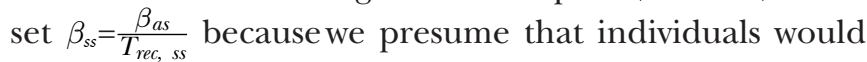
be most at risk of infecting other susceptible individuals during their transport to the hospital and so this ratio that a patient who is severely ill would infect as many individuals over the course of their being in the severely symptomatic subcompartment as an asymptomatic but infectious patient would in 1 day.

We chose South Korea as a benchmark to validate $\beta_{m s}, \beta_{s s}$ and other parameters of our model because it is cited as an example for its extensive testing, tracking and tracing of infections. We calibrate $R_{t}$ by allowing it to change at each new containment measure taken by South Korean authorities until the number of identified cases reaches 
Table 1 Parameters of the model

\begin{tabular}{|c|c|c|c|c|c|}
\hline \multirow[b]{2}{*}{ First case } & Ghana & Kenya & Senegal & South Korea & Source \\
\hline & 13 March 2020 & 14 March-20 & 02 March-20 & $\begin{array}{l}20 \text { January } \\
2020\end{array}$ & $\begin{array}{l}\text { European CDC (2020), } \\
\text { Senegalese Ministry of } \\
\text { Health (2020) }\end{array}$ \\
\hline Population & 30.497 million & 51.808 million & 17.354 million & 51.410 million & CountryMeters $^{43}$ \\
\hline$\mu_{\text {birth }}$ & $9.01 \mathrm{E}-05$ & $9.71 \mathrm{E}-05$ & $1.00 \mathrm{E}-04$ & $2.51 \mathrm{E}-05$ & CountryMeters $^{43}$ \\
\hline$\mu_{\text {death }}$ & $9.01 \mathrm{E}-05$ & $9.71 \mathrm{E}-05$ & $1.00 \mathrm{E}-04$ & $1.60 \mathrm{E}-05$ & The World Bank ${ }^{36}$ \\
\hline$r_{\text {as }}$ & 0.4 & 0.4 & 0.4 & 0.4 & Nishiura et $a l^{17}$ \\
\hline$T_{\text {rec,as }}$ & 14 days & 14 days & 14 days & 14 days & Hubei: Mclntosh ${ }^{44}$ \\
\hline$T_{\text {inc }}$ & 5 days & 5 days & 5 days & 5 days & Mclntosh $^{44}$ \\
\hline$T_{\mathrm{d}}$ & 6 days & 6 days & 6 days & 6 days & Mclntosh $^{44}$ \\
\hline$T_{\text {rec,ms }}$ & 16 days & 16 days & 16 days & 16 days & Mclntosh $^{44}$ \\
\hline$T_{\text {sev }}$ & 5 days & 5 days & 5 days & 5 days & Mclntosh $^{44}$ \\
\hline$T_{\text {rec,ss }}$ & 18 days & 18 days & 18 days & 18 days & Mclntosh $^{44}$ \\
\hline$\alpha$ & 2 & 2 & 2 & 2 & Mclntosh $^{44}$ \\
\hline$d_{\mathrm{ms}}$ & $0.37 \%$ & $0.37 \%$ & $0.37 \%$ & $0.03 \%$ & CountryMeters ${ }^{43}$ \\
\hline$d_{\mathrm{ss}}$ & $2 \%$ & $2 \%$ & $2 \%$ & $1.04 \%$ & CountryMeters $^{43}$ \\
\hline$r_{\mathrm{ms}}$ & $98.34 \%$ & $98.53 \%$ & $98.62 \%$ & $94.33 \%$ & Verity et $a l^{45}$ \\
\hline$R_{t}$ & $\begin{array}{l}1.25(1.0-1.4) \text { if } 0 \leq d<7 \\
2.35(2.2-2.7) \text { if } 7 \leq d<9 \\
2.3(1.7-2.5) \text { if } 9 \leq d<16 \\
1.6(1.0-2.2) \text { if } 16 \leq d\end{array}$ & $\begin{array}{l}2.4(2.2-2.6) \text { if } 0 \leq d<7 \\
2.15(1.8-2.5) \text { if } 7 \leq d<9 \\
2(1.6-2.4) \text { if } 9 \leq d<14 \\
1.6(1.0-2.2) \text { if } 14 \leq d\end{array}$ & $\begin{array}{l}1.29(1.1-1.48) \text { if } 0 \leq d<20 \\
2.4(2.1-2.7) \text { if } 20 \leq d<26 \\
1.5(1.0-2.00) \text { if } 26 \leq d\end{array}$ & $\begin{array}{l}1.13 \text { if } 0 \leq d<30 \\
3.02 \text { if } 30 \leq d<41 \\
1.85 \text { if } 41 \leq d<44 \\
0.88 \text { if } 44 \leq d<49 \\
0.3 \text { if } 49 \leq d<59\end{array}$ & $\begin{array}{l}\text { Author's estimates, adjusting } \\
R_{t} \text { with timeline of government } \\
\text { policies outlined in figure } 2\end{array}$ \\
\hline $\begin{array}{l}\beta_{\mathrm{ms}} \\
\beta_{\mathrm{ss}}\end{array}$ & $\begin{array}{l}0.41 \beta_{\text {as }} \\
\beta_{\text {as }} / T_{\text {rec }, \mathrm{ss}}\end{array}$ & $\begin{array}{l}0.41 \beta_{\text {as }} \\
\beta_{\mathrm{as}} / T_{\text {rec,ss }}\end{array}$ & $\begin{array}{l}0.41 \beta_{\text {as }} \\
\beta_{\text {as }} / T_{\text {rec,ss }}\end{array}$ & $\begin{array}{l}0.41 \beta_{\text {as }} \\
\beta_{\text {as }} / T_{\text {rec,ss }}\end{array}$ & $\begin{array}{l}\text { Author's estimate using Wang } \\
\text { et } a l^{24}\end{array}$ \\
\hline
\end{tabular}

$R_{\mathrm{t}}$ in parenthesis are $R_{\mathrm{t}}$ values for optimistic and pessimistic scenarios, respectively.

a plateau. We solve an optimisation problem constrained by equations (1)-(5) using the MATLAB optimisation codes of D'Errico. ${ }^{25}$ The values of $R_{t}$ obtained and other parameters are summarised in table 1 . The number of infections computed with our model accurately approximates the positive cases in South Korea (see figure 1).

For the fatality rates $d_{s s}$ and $d_{m s}$ in Ghana, Kenya and Senegal, we split the reported regional fatality rate (As of 25 April 2020, the Western African fatality rate is 2.49\%

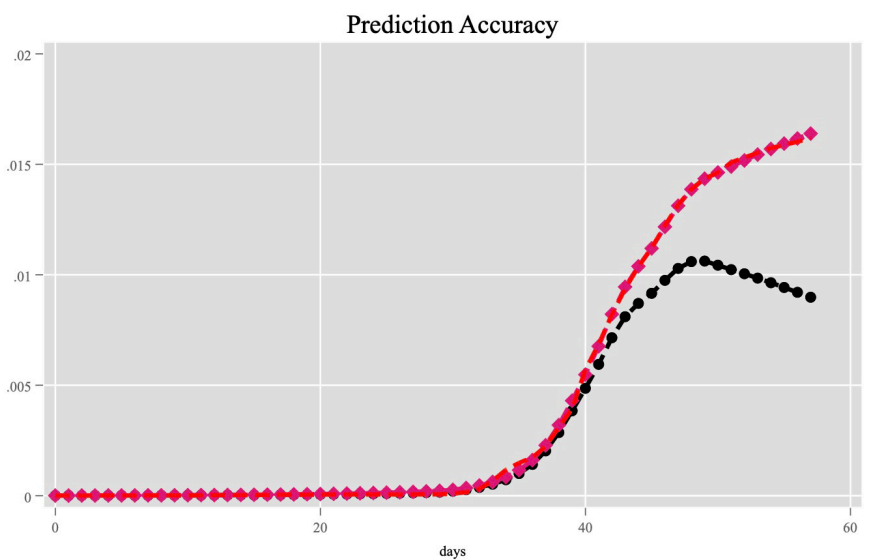

while the Eastern African fatality rate is $2.25 \%$, we take the average of both these numbers. Note that we use the regional figures because the number of cases at the national level is still low in the three countries. Western Africa has 8034 cases and Eastern Africa has 3319 cases as of 27 April 2020 (Africa CDC). Although these numbers are much lower than the Africa-wide (32 182 cases) and the worldwide ones, we find them more appropriate as they are more faithful to the standards of living and

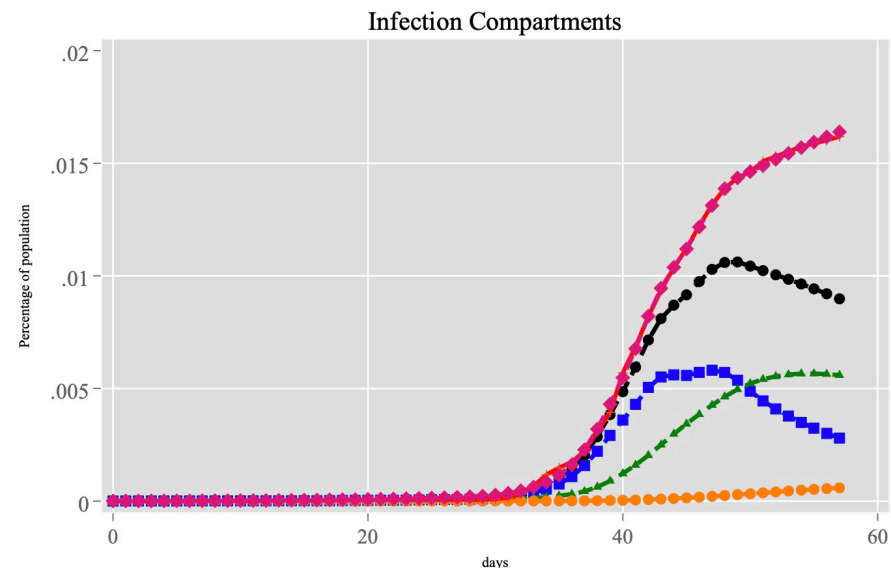

Active Cases (Predicted Baseline)

Severe Cases (Predicted Baseline) $\rightarrow$ Without Symptoms (Predicted Baseline) Cumulative Positive Tests (Actual)
-With Symptoms (Predicted Baseline) Cumulative Cases (Predicted Cases)

Figure 1 Benchmark, South Korea. 
the age pyramid of the countries we study. Particularly, Algeria (12.57\% fatality rate) and Egypt (6.99\%), among others, raise the Africa-wide fatality rate to $4.44 \%$ but are structurally different from Ghana, Kenya and Senegal. That being said, we acknowledge that our choice relies on the testing capacity in both Western and Eastern African regions and might underestimate the true fatality rate as a consequence) $2.37 \%$ between $d_{s s}=2 \%$ and $d_{m s}=0.37 \%$ as most deaths occurred for the severely symptomatic. (Note that there are two ways to compute the fatality rate, either (1) as the ratio deaths/total cases, or (2) deaths/ closed cases. While the former is likely to be an underestimate because lots of open cases can still end up in death, the latter is an overestimate because it is likely that deaths are closed quicker than recoveries. As critical cases are more likely to be detected than mild infections, it is also likely that the number of true cases is underestimated by official numbers but the number of COVID-19-related deaths is relatively well captured by official reports. Therefore, the ratio (1) is likely to be a better estimate of the true fatality rate than (2), and we use this definition of fatality rate. ${ }^{26}$ However, in South Korea, we use the South Korean COVID-19 fatality rate- $1.07 \%$ as of 2 April 2020—and split it across $d_{m s}=0.03 \%$ and $d_{s s}=1.04 \%$.

$I_{m s}$ was initialised with the number of cases tested positive on the first day of the epidemic in the country.

$I_{a s}$ was initialised with the number of cases $T_{i n c}=5$ days after this same date. $I_{s s}$ was initialised at 0 .

For Ghana and Senegal, $R_{t}$ is tuned to match the number of official cases until the first reported case of community transmission (see table 1), that is the transmission that cannot be traced back to one of the initial cases. Then, $R_{t}$ is increased once and then lowered as soon as the first containment policy is enacted in the country and further lowered at each additional containment measure. Because Kenya first reported community transmission case coincided with the enforcement of a curfew to limit the spread of the virus, we only change $R_{t}$ once for both the community transmission and the curfew.

Since they alter $R_{t}$, our baseline projections account for mitigation policies that were put in place in each of these countries (see figure 2). Similarly, $R_{t}$ is tailored to each of the three countries according to the different policies they enforced. For example, in Kenya, we decrease it less for school closings than for regional lockdowns.

At the date of each containment measure, we adjust the value of $R_{t}$ and provide low policy and high policy effectiveness scenarios. Our baseline projections assume a moderate impact of the policy, while the high effectiveness projections correspond to the case in which containment measures reduce the reproduction number significantly-that is the situation in which the policy has had large positive impacts to reduce the effective rate of reproduction (see table 1). Our low policy effectiveness scenario translates the instance in which, on the contrary, the impact of each policy on the reproduction number is minimal.

Results reported in figure 3 show how the predictions fit the detected cases in the early days of the pandemic.

We report predictions for a year (see figure 3). Under the assumptions of the baseline model and their limitations, we predict that the peak of the epidemic will occur in July for all three countries as detailed in table 2. For Ghana, Kenya and Senegal, respectively, this peak should lead to approximately 11.1, 18.9 and 5.8 million active infections (including asymptomatic and symptomatic cases) at the peak of the epidemic, with 308000,465 000 and 138000 individuals severely ill needing medical attention (see figure 3 ).

These long-term scenarios should be interpreted with great caution as they do not consider future policies or actions that could drastically reduce the contact rates and subsequently, flatten the curve further. (For instance, wearing a mask in public space is now mandatory in Kenya (since 15 April), Senegal (since 20 April) and Ghana (since 25 April). Additionally, the government of Ghana lifted its partial lockdown on 20 April.)

\section{Testing the sensitivity of the simulations to $\boldsymbol{R}_{t}$}

We perform a sensitivity analysis for $R_{t}$ on our baseline model. We perturb it 100 times by $\varepsilon$ drawn uniformly in $\left[-5 \% R_{t},+5 \% R_{t}\right]$. The number of infections at the peak fluctuates between $27 \%$ and $40 \%$ of the total population in the active infection compartment for Ghana, between $28 \%$ and $40 \%$ for Kenya and between $25 \%$ and $37 \%$ for

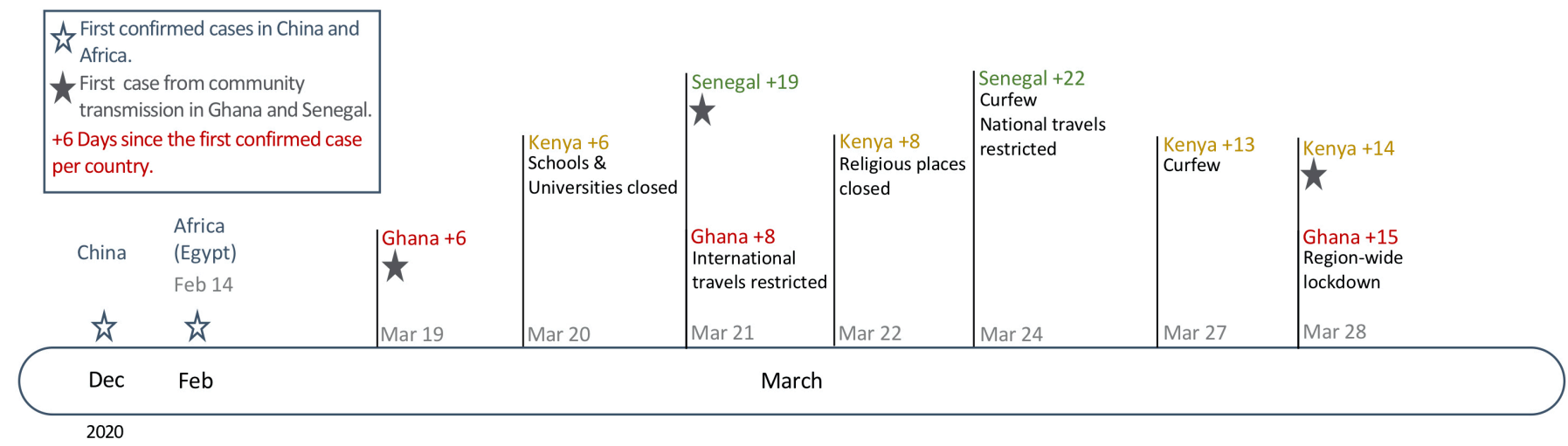

Figure 2 Timing of policies across countries. 


\section{Cumulative Infections, Short-term}
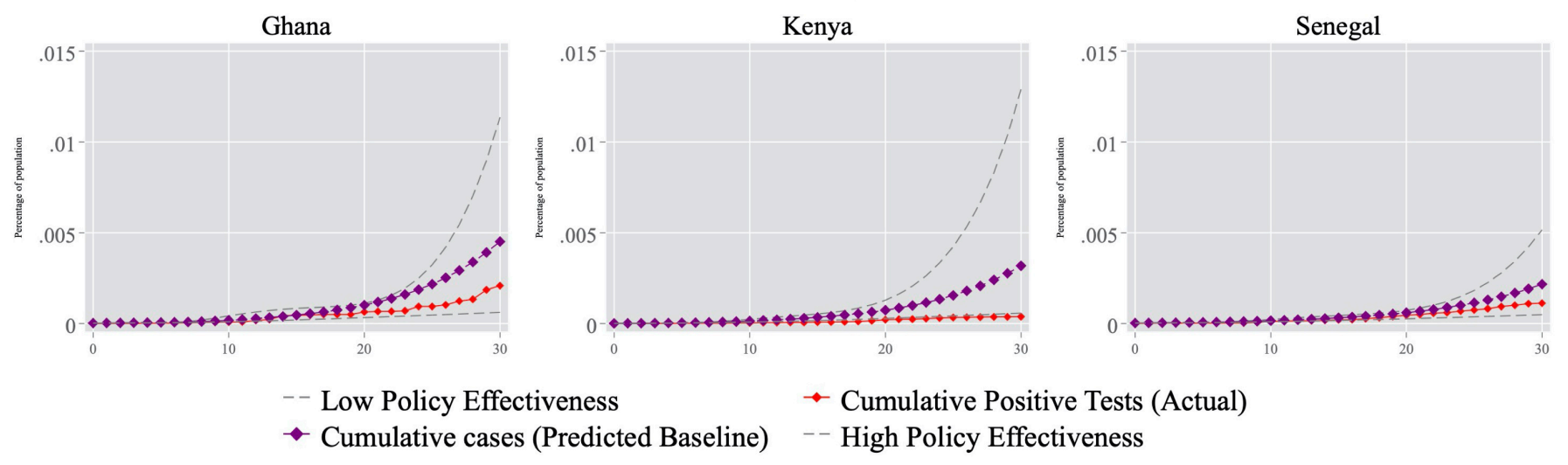

- Cumulative cases (Predicted Baseline) -- High Policy Effectiveness

\section{Cumulative Infections, Long-term}
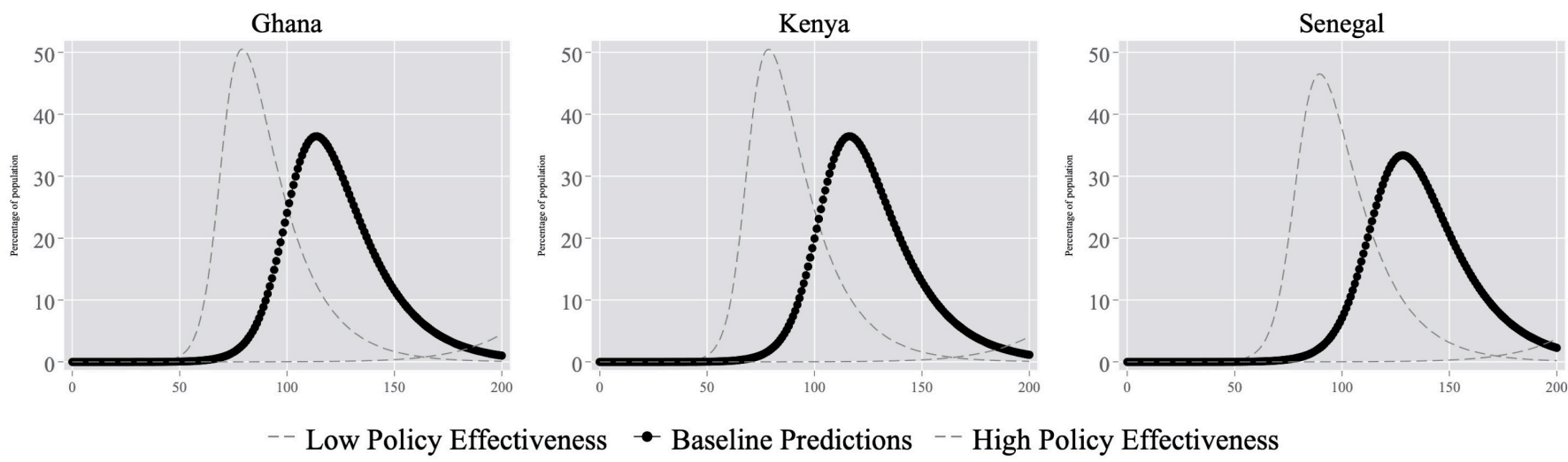

Active Infections by Compartment, Long Term

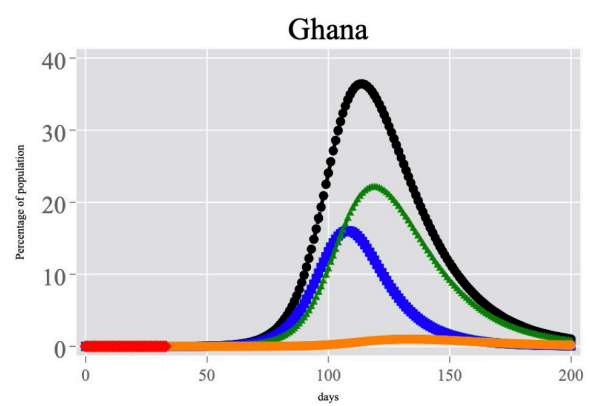

- Baseline Predictions

- Severe Symptoms (baseline predictions)

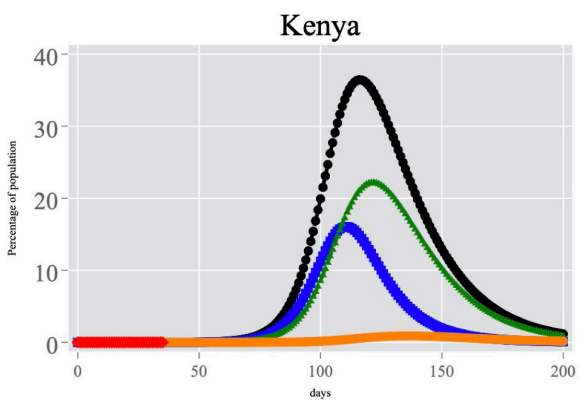

$\rightarrow$ No Symptoms (baseline predictions)
$\rightarrow$ Cumulative Positive Tests (Actual)

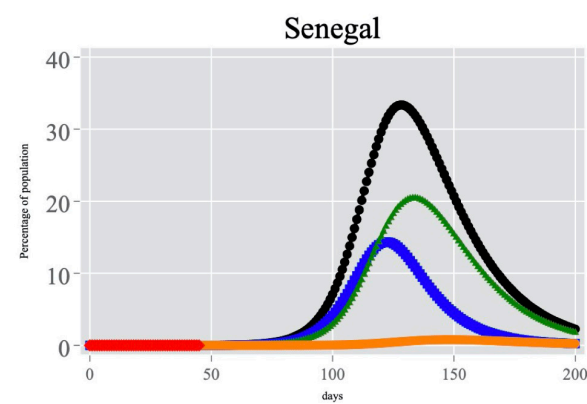

- Mild Symptoms (baseline predictions)

Figure 3 Projection of active infections.

Senegal (see online supplementary appendix figure 2). In countries that enforced strict social distancing measures, predictions were significantly updated down-from about 2.2 million deaths on $16 \mathrm{March}^{12}$ to about 60000 on 30 March. $^{27}$ A similar update can be expected from the outputs of our model as authorities take effective measures to reduce $R_{t}$ and/or people in these countries gradually adopt behaviour that would minimise contacts.

\section{Population density and rate of reproduction}

As the population density increases, the rate of transmission of infectious diseases increases. ${ }^{28}$ With respectively $43.3 \%, 72.2 \%$ and $50.6 \%$ as a share of their population living in rural areas, Ghana, Kenya and Senegal have sparsely populated areas outside of their main metropolitan areas, compared with countries like South Korea ( $18.5 \%$ of rural population).

There is little information on the relative rate of transmission of COVID-19 between rural and urban areas but we draw on other diseases, for which there are available data. During the 2014 Ebola outbreak in Sierra Leone, ${ }^{29}$ we find that the basic reproduction number in Kambia (the least densely populated district of Sierra Leone) is 0.56 times the one in the Western Area Urban district (the most densely populated district that comprises the capital 
Table 2 Projections of active cases at the peak of the epidemic for each infected compartment

\begin{tabular}{|c|c|c|c|c|c|}
\hline & & Days since first & Active cases at pe & & \\
\hline & & case & Severe symptoms & Mild symptoms & No symptoms \\
\hline Ghana & Low policy effectiveness & 79 & 0.4 million & 9.1 million & 7.7 million \\
\hline & Baseline & 114 & 0.3 million & 6.7 million & 4.9 million \\
\hline & High policy effectiveness & 250 & 0.1 million & 2.7 million & 1.6 million \\
\hline Kenya & Low policy effectiveness & 79 & 0.6 million & 15.4 million & 13.1 million \\
\hline & Baseline & 116 & 0.5 million & 11.7 million & 8.3 million \\
\hline & High policy effectiveness & 252 & 0.2 million & 4.6 million & 2.7 million \\
\hline Senegal & Low policy effectiveness & 90 & 0.2 million & 4.8 million & 3.9 million \\
\hline & Baseline & 128 & 0.1 million & 3.5 million & 2.5 million \\
\hline & High policy effectiveness & 254 & 0.1 million & 1.5 million & 1.0 million \\
\hline
\end{tabular}

The peaks of each infection subcompartment might not align.

Freetown). (We chose the most and the least populated districts because all these districts include urban areas.) We take that to mean that the $R_{t}$ in rural areas was 0.56 times that in urban areas. Other mostly rural districts had a higher $R_{t}$. To mirror the range of ratios of reproduction rates observed in mostly rural and mostly urban districts for the Ebola epidemic in Sierra Leone, we run two simulations, one in which the rural to urban ratio is 0.50 , and one where it is 0.75 . These two ratios bound the difference between mostly rural districts and mostly urban areas for Ebola in Sierra Leone. ${ }^{29}$ Using these ratios, we calibrate the rural and urban reproduction rates so their population weighted average is equal to the national $R_{t}$ which we keep constant across our baseline scenario and this scenario:

$$
\left\{\begin{array}{l}
R_{t, \text { rur }}=\gamma R_{t, u r b} \\
R_{t}=r_{u r b} R_{t, u r b}+\left(1-r_{u r b}\right) R_{t, r u r}
\end{array}\right.
$$

where $R_{t, r u r}$ and $R_{t, u r b}$ are the rural and urban reproduction rates, respectively; $\gamma=0.50$, or $\gamma=0.75 ; r_{u r b}$ is the national urbanisation rate; $R_{t}$ is the national reproduction rate listed in table 1 . We use the first day of the first community transmission as the day of the first case in the rural area. Results are compiled in table 3. Effectively, we see in figure 4 that when accounting for rural areas, we observe two peaks. The first peak is driven by the spread in urban areas while the second peak, delayed in time, is driven by the spread in rural areas. Kenya, with a rural share of the population of over $70 \%$, has the most noticeable split across its rural and urban areas.

\section{Comorbidity and rise in the occurrence of severe symptoms}

Comorbidity can impact the share of mild cases that develop severe symptoms. ${ }^{30}$ In Asia and Europe, hypertension, obesity, diabetes and coronary heart diseases have been drivers of adverse health outcomes. ${ }^{30}{ }^{31}$ Because the combined prevalence of diabetes, hypertension and obesity is not higher in Ghana, Kenya and Senegal than they are in regions we use to derive the recovery rates, the baseline simulations already account for them. However, Ghana, Kenya and Senegal have persistent and high rates of anaemia and $\mathrm{TB}^{3}$. To our knowledge, there is no study on the magnitude of the impacts of anaemia, ТB or HIV on the recovery of patients who have contracted the virus. We simulate two scenarios, with $25 \%$ and $75 \%$ of the recovery rate of otherwise healthy individuals for

Table 3 Projection of infections accounting for Africa-specific factors

\begin{tabular}{|c|c|c|c|c|c|c|c|c|c|}
\hline & \multirow[b]{4}{*}{$\frac{R_{t}(\text { rural })}{R_{t}(\text { urban })}$} & \multicolumn{8}{|c|}{ Comorbidity } \\
\hline & & \multicolumn{8}{|c|}{$\%$ of the survival rate of healthy patients } \\
\hline & & \multicolumn{4}{|l|}{$75 \%$} & \multicolumn{4}{|l|}{$25 \%$} \\
\hline & & Severe & Mild & Asymptomatic & Days* & Severe & Mild & Asymptomatic & Days* \\
\hline \multirow[t]{2}{*}{ Ghana } & $50 \%$ & 0.2 million & 4.4 million & 3.3 million & 81 & 0.3 million & 4.8 million & 3.9 million & 81 \\
\hline & $75 \%$ & 0.2 million & 4.8 million & 3.9 million & 96 & 0.3 million & 4.4 million & 3.3 million & 96 \\
\hline \multirow[t]{2}{*}{ Kenya } & $50 \%$ & 0.4 million & 8.2 million & 5.3 million & 167 & 0.4 million & 5.5 million & 4.2 million & 168 \\
\hline & $75 \%$ & 0.3 million & 5.6 million & 4.2 million & 130 & 0.6 million & 8 million & 5.3 million & 131 \\
\hline \multirow[t]{2}{*}{ Senegal } & $50 \%$ & 0.1 million & 2.2 million & 1.6 million & 87 & 0.1 million & 2.3 million & 1.9 million & 87 \\
\hline & $75 \%$ & 0.1 million & 2.4 million & 1.9 million & 105 & 0.1 million & 2.1 million & 1.6 million & 105 \\
\hline
\end{tabular}

The peaks of each infection subcompartment might not align.

*Days of total infection peak, since the first case tested positive. March 2 for Senegal, March 13 for Ghana and March 14 for Kenya. 
Active Infections with Rural Areas, Long Term
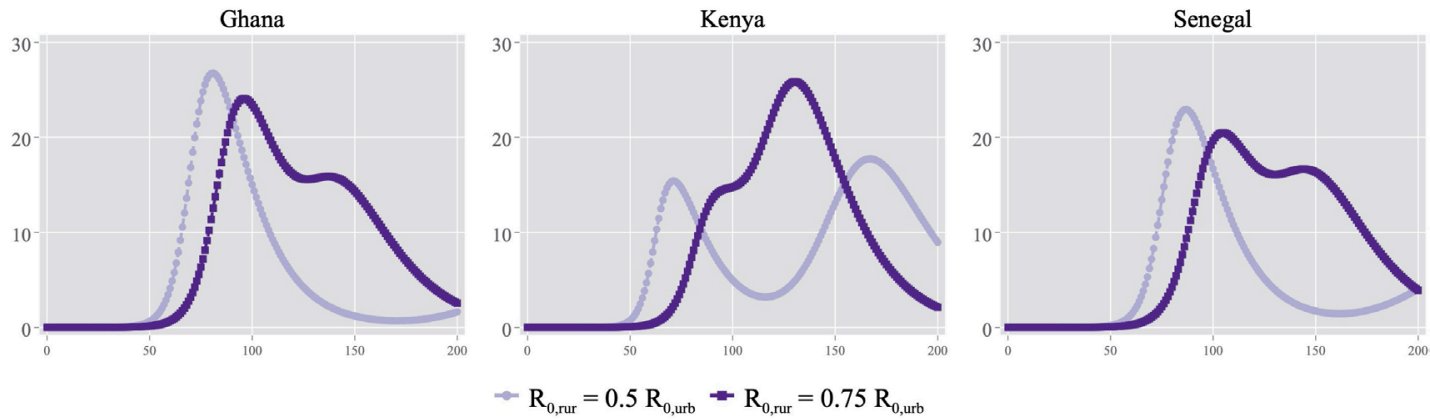

Severe Cases with co-Morbidities, Long Term
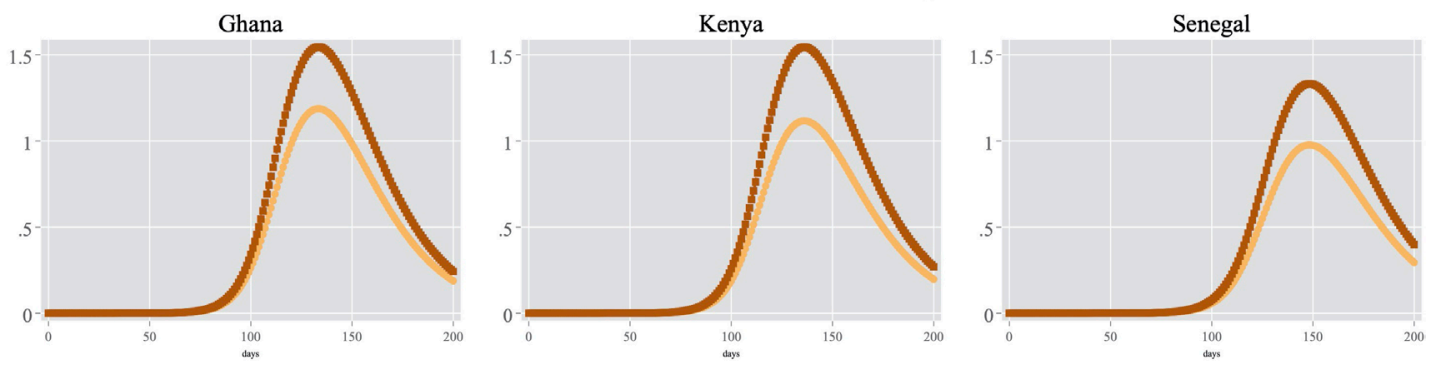

$\Rightarrow \mathrm{r}_{\mathrm{ms}, \mathrm{morb}}=.75 \mathrm{r}_{\mathrm{ms}}-\mathrm{r}_{\mathrm{ms}, \mathrm{morb}}=.25 \mathrm{r}_{\mathrm{ms}}$

Severe Cases with co-Morbidities and Rural Areas, Long Term

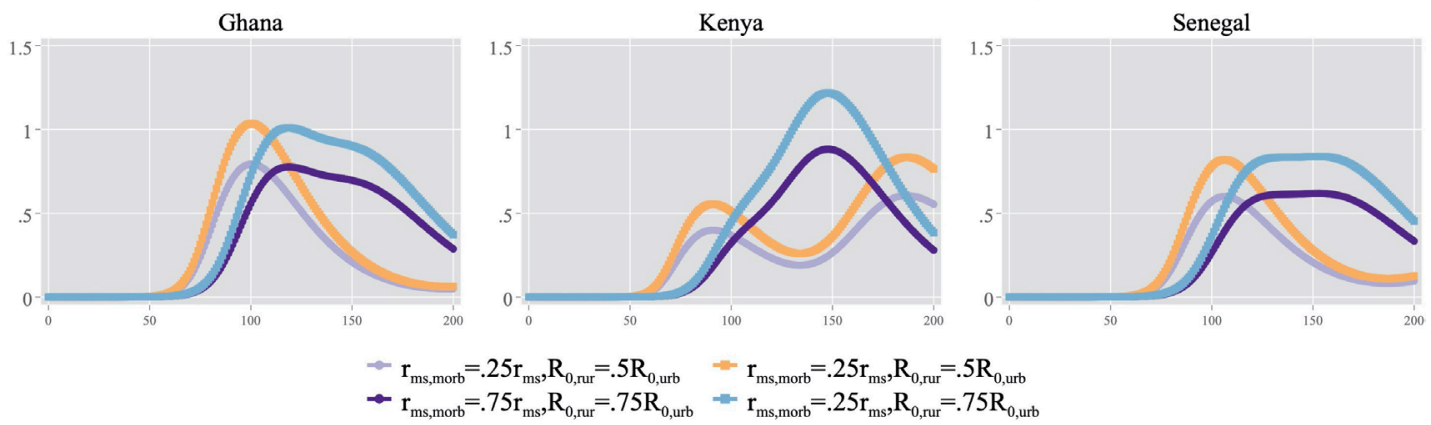

Figure 4 Projected active infections accounting for underlying conditions and rural areas. Y-axis is per cent of total population.

individuals with one of these underlying conditions ${ }^{1}$. In comparison, Zhou et $a \hat{l}^{30}$ find that in Wuhan, China, patients with comorbidities (hypertension, diabetes, coronary heart disease, chronic obstructive lung disease, carcinoma, chronic kidney diseases and others) have a recovery rate equal to $73.2 \%$ of their otherwise healthy counterparts. Though uncertain for HIV, anaemia and $\mathrm{TB}$, the impact of these underlying conditions on the recovery of individuals will likely lie between these two bounds. This translates into adjusting $r_{m s}$ for individuals with TB, HIV and anaemia. Comorbidities have agespecific incidence rates; anaemia affects women of childbearing age primarily, while HIV affects young adults at higher rates. The prevalence of HIV, TB and anaemia is extracted from the open database Global Burden Disease. ${ }^{32}$ We account for these age-based differences to compute the recovery rate of the population accounting for comorbidities:

$$
r_{m s, \text { morb }}=\sum_{a g} w_{a g} r_{a g}\left(1-i_{\text {morb }} x_{a g, m o r b}\right)
$$

where $r_{m s, \text { morb }}$ is the rate of recovery for infected individuals who develop mild symptoms and have one of the three comorbidities. $r_{a g}$ is the recovery rate of the otherwise healthy individuals in the age group, $i_{\text {morb }}$ is either $1-0.25$ or $1-0.75$ depending on the scenario and $x_{a g}$, morb is the share of individuals in each age group with the comorbidity.

We report the results in figure 4 and table 3 . As expected, the predictions are higher in the case where we assume that individuals with comorbidities have a rate of recovery that is $25 \%$ that of otherwise healthy individuals. In the scenario with $R_{t, r u r}=0.75 R_{t, u r b}$, the number of active severe cases at the peak is 0.242 million with a $75 \%$ recovery scenario for Ghana (0.308 million for the $25 \%$ scenario), 0.313 million for Kenya (0.631 million) and 0.104 million (0.145 million) for Senegal. Kenya's large impact is driven by its larger HIV-positive population.

\section{Mirroring South Korea's effectiveness}

Unlike countries in Europe, Ghana, Kenya and Senegal have taken containment measures very early in the 

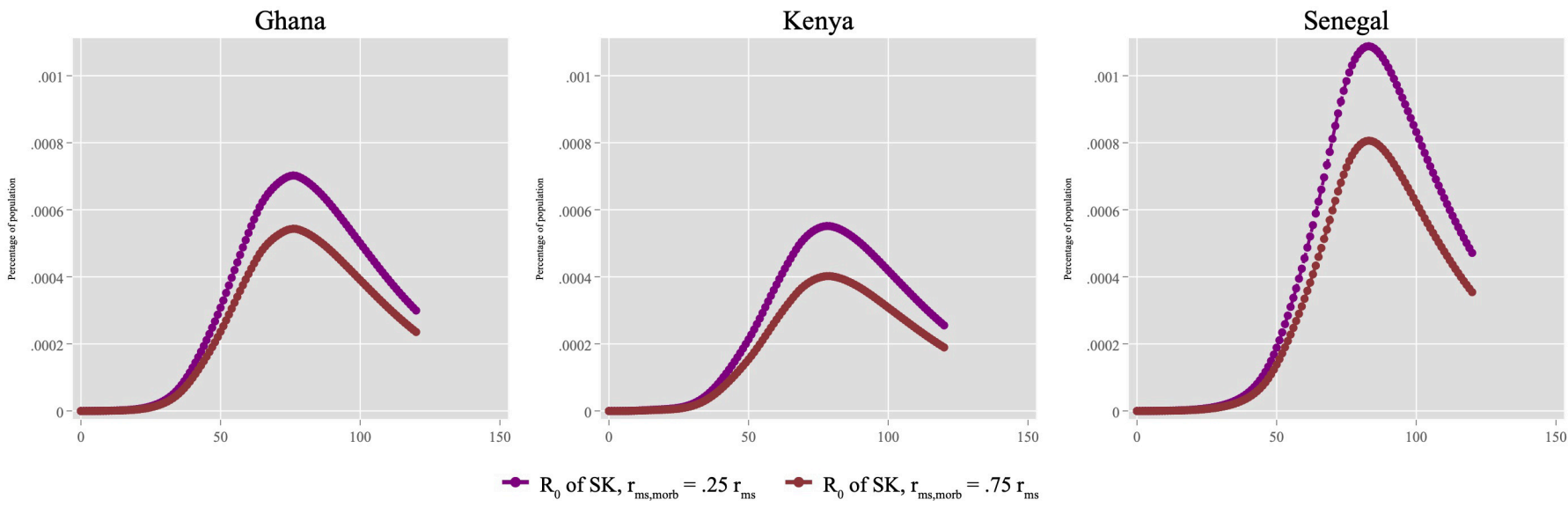

Figure 5 Projected severe active infections mirroring South Korean's $R_{t}$.

progression of the disease. The policies could have had impacts similar to the ones in South Korea. We present results of simulations mirroring the $R_{t}$ for South Korea. Specifically, we decrease $R_{t}$ for each country 3 weeks after the last recorded policy to 0.88 , and then again at 6 weeks to 0.3 . We find that the peak is much lower, with a number of active severe infections at the peak between 166 and 214 individuals for Ghana, 208 and 286 individuals for Kenya and 140 and 189 individuals for Senegal; with the two bounds being for recovery rates of respectively $75 \%$ and $25 \%$ of that of the otherwise healthy patients. These peaks will occur 2-3 months after the first case (see figure 5 and table 4 ). This scenario is attainable only if these countries are able to maintain effective policies for an extended period.

\section{DISCUSSION}

In this study, we account for the age structure of the population in each country, the burden of potential comorbidities and the differential spreads of the virus in rural and urban areas. We find that the relatively young population may limit the severity of the epidemic by lowering the number of infections that lead to severe symptoms. We also find that sparsely populated areas may limit the spread of the epidemic. Rural areas effectively may lead to staggered peaks; this has important implications for policymakers who may be faced with two waves, and so may need to adapt their responses to adaptively deploy personnel on their territory as these peaks occur.

High rates of comorbidities however may lead to more individuals developing severe symptoms relative to a scenario with no comorbidities. We find that at the peak, Ghana, Kenya and Senegal are predicted to have respectively between $0.78 \%$ and $1.03 \%, 0.89 \%$ and $1.22 \%$ and, finally, $0.60 \%$ and $0.84 \%$ active clinical severe cases of COVID-19 with a peak of total infections predicted to occur between 2 June and 17 June (Ghana), 22 July and 29 August (Kenya) and 28 May and 15 June (Senegal), respectively, against a July timeline for our baseline specification. Successful containment policies could lead to even lower rates of severe infections.

Though recent models look at a few countries in Africa,${ }^{33}$ or at the continent as a whole,${ }^{34}{ }^{35}$ there are little to no studies predicting the spread of COVID-19 in Ghana and Senegal while incorporating specificities of these two countries. In Kenya, however, Brand et al ${ }^{10}$ account for age-based population mixing and assume that asymptomatic individuals are as infectious as symptomatic individuals to predict that by the end of the year, 46.1 million (ie, $89 \%$ of the public) of infections will have occurred. This prediction is comparable with the baseline results of our study in the absence of further containment policies. In that scenario, we find that about 47.7 million (93\% of the public) individuals may be infected cumulatively.

Table 4 Projection of active cases at peak accounting for comorbidities, with South Korea's $R_{\mathrm{t}}$

\begin{tabular}{|c|c|c|c|c|c|c|c|c|c|}
\hline & \multirow{4}{*}{$\frac{R_{t}(\text { rural })}{R_{t}(\text { urban })}$} & \multicolumn{8}{|c|}{ Comorbidity } \\
\hline & & \multicolumn{8}{|c|}{$\%$ of the survival rate of healthy patients } \\
\hline & & \multicolumn{4}{|l|}{$75 \%$} & \multicolumn{4}{|l|}{$25 \%$} \\
\hline & & Severe & Mild & Asymptomatic & Days* & Severe & Mild & Asymptomatic & Days* \\
\hline Ghana & $100 \%$ & 166 & 3164 & 2428 & 57 & 214 & 3110 & 3110 & 57 \\
\hline Kenya & $100 \%$ & 208 & 4221 & 3206 & 60 & 286 & 4134 & 4134 & 60 \\
\hline Senegal & $100 \%$ & 140 & 3253 & 2661 & 69 & 189 & 3183 & 3183 & 69 \\
\hline
\end{tabular}

The peak of each active case for each subcompartment might not align.

* Days of total infection peak, since the first case tested positive. March 2 for Senegal, March 13 for Ghana and March 14 for Kenya. 
Containment measures will be successful only if the public comply; however, measuring compliance is complex and has not been rigorously studied in the context of COVD-19 in these countries. In Ghana, Kenya and Senegal poverty is the main challenge to compliance, with official unemployment rates reaching $68.7 \%$, $51.3 \%$ and $64.6 \%$, respectively. ${ }^{36}$ As a response, authorities have implemented emergency transfer programmes in cash and in-kind to the most vulnerable households partly to address compliance but also to avoid a humanitarian crisis (Senegal, Ghana). In urban areas, officials have required buses and taxis to reduce their number of passengers (Kenya, Senegal) and have mandated the use of masks (Ghana, Senegal).

Looking at how spike in cases was met by various healthcare systems in Europe and Asia, it is likely that most asymptomatic and mild cases may remain undetected.

\section{Limitations}

Our model does not incorporate changes in the survival rate of the virus due to weather or humidity, and in that regard, our simulations are a worst-case scenario. ${ }^{37} 38$ Additionally, the model assumes homogeneous mixing of individuals within rural and urban areas which is an unlikely assumption. In a future iteration of our model, we plan to use a spatially structured model in order to relax the homogeneous mixing assumption by leveraging phone data. ${ }^{20} 3940$

The model also excludes international population flows. All countries in our sample have closed their international borders-airports and roads-before or a few days after their first confirmed imported case (see figure 2). However, it is possible that COVID-19 was spreading undetected for days in the respective countries. If that is true, the peak of active cases might be delayed in comparison to the true peak. Furthermore, the spread of this disease is highly dependent on the reproduction number $R_{t}$. Since this number is contingent on many factors (policies, individuals' behaviour, and so on), its value in the long run is subject to large uncertainties. The projected number of infections in the medium to long term could thus be considerable overestimates (or underestimates) of the true number of infections (depending on the scenarios).

These predictions aggregate infections in rural and urban areas, however, in practice, the peaks in urban areas, due to higher reproduction rates, will occur earlier. In rural areas, however, the peaks will be delayed due to their lower $R_{t}$. This distinction is important for policymakers who can target their resources accordingly.

The use of the data also comes with limitations such as the inaccuracy of the data collection. For example, one person was tested positive for COVID-19 on 4 March but entered Senegal on 24 February. We expect that all the countries in our sample are dealing with similar delays, however, we did not find a consistent way to address this issue. Additionally, given the low number of tests performed to detect the virus, we cannot ex ante measure the accuracy of our model in Ghana, Kenya and Senegal.

Because outcomes of individuals with critical needs are highly dependent on the capacity of healthcare systems, having data on healthcare capacity is important in predicting the number of fatalities. In our simulations, information such as the number of ICU beds would inform the fatality rate of individuals with severe symptoms $\left(d_{s s}\right)$. Unfortunately, we do not have access to such data and we thus choose not to show the results for fatality rates in these three countries. Finally, we use an SIR, which assumes perpetual immunity-however, there are still uncertainties regarding the possibility of reinfection. ${ }^{41}$

\section{CONCLUSION}

In conclusion, containment measures, age structures, low urbanisation and comorbidity may lead Ghana, Kenya and Senegal to having different trajectories from the USA, and from Asian and European countries. This study is a first attempt at accounting for rural densities and comorbidity, and it suggests that rural areas will slow down the spread of the epidemic, and that relatively young population will keep the number of severe cases low compared with the nearly $3.5 \%$ hospitalisation rate in Europe and Central Asia. ${ }^{42}$ Our findings also show how sensitive these results are to different assumptions on the effectiveness of policies, assumptions on comorbidities and differential effective rates of reproduction in rural and urban areas.

Acknowledgements We thank Martin J. Williams, Kevin Marsh, Mike English, Renaud Lambiotte, Philip Bejon, Douglas Gollin and Isabel Ruiz for reviewing the manuscript.

Contributors The authors contributed equally to this study.

Funding Binta Zahra Diop's PhD is funded by the Center for the Study of African Economies and the Global Challenges Research Fund. Marieme Ngom's work was supported by the U.S. Department of Energy, Office of Science, under Contract DE-AC02-06CH11357. Clémence Pougué Biyong's PhD is funded by the French Ministry of Higher Education and Ecole Normale Supérieure of Rennes. John N. Pougué Biyong's PhD is funded by the UK Engineering and Physical Sciences Research Council (EPSRC).

Competing interests None declared.

Patient consent for publication Not required.

Provenance and peer review Commissioned; externally peer reviewed.

Data availability statement Data are available in a public, open access repository. We are using publicly available data exclusively. The sources of these data are the following: (1) the European Centre for Disease Prevention and Control: https://www.ecdc.europa.eu/en/publications-data/download-todays-datageographic-distribution-covid-19-cases-worldwide; (2) the Senegalese Ministry of Health: http://www.sante.gouv.sn/Pr\%C3\%A9sentation/coronavirus-informationsofficielles-et-quotidiennes-du-msas; (3) the Ghana Health Service: https:// ghanahealthservice.org/covid19/; (4) the Kenyan Ministry of Health: https://www. health.go.ke/; (5) Our World in Data: https://ourworldindata.org/coronavirus; (6) Worldometers: https://www.worldometers.info/

Open access This is an open access article distributed in accordance with the Creative Commons Attribution Non Commercial (CC BY-NC 4.0) license, which permits others to distribute, remix, adapt, build upon this work non-commercially, and license their derivative works on different terms, provided the original work is properly cited, appropriate credit is given, any changes made indicated, and the use is non-commercial. See: http://creativecommons.org/licenses/by-nc/4.0/. 
ORCID iD

Binta Zahra Diop http://orcid.org/0000-0003-4245-6690

\section{REFERENCES}

1 Johns Hopkins Coronavirus Resource Center. COVID-19 Dashboard by the center for systems science and engineering (CSSE), 2020. Available: https://coronavirus.jhu.edu/map.html [Accessed $27 \mathrm{Apr}$ 2020].

2 United Nations Economic Commission for Africa. The demographic profile of African countries, 2015. Available: https://www.uneca.org/ publications/demographic-profi\%1Fle-african-countries [Accessed 25 Apr 2020].

3 Lancet global burden of disease. Available: https://www.thelancet. com/gbd?source=post page [Accessed 27 Apr 2020].

4 El Bcheraoui C, Mimche H, Miangotar Y, et al. Burden of disease in francophone Africa, 1990-2017: a systematic analysis for the global burden of disease study 2017. Lancet Glob Health 2020;8:e341-51.

5 World Demographics. (Population, Age, Sex, Trends) - Worldometer 2020, 2020. Available: https://www.worldometers.info/ demographics/world-demographics/ [Accessed 27 Apr 2020].

6 Lee P-I, Hu Y-L, Chen P-Y, et al. Are children less susceptible to COVID-19? J Microbiol Immunol Infect 2020.

7 Africa's debt crisis hampers its fight against covid-19. The Economist 2020.

8 Barasa E, Ouma PO, Okiro EA. Assessing the hospital surge capacity of the Kenyan health system in the face of the COVID-19 pandemic. MedRxiv 2020.

9 Tackling the coronavirus (COVID-19) crisis together: OECD policy contributions for co-ordinated action, 2020. Available: http://www. oecd.org/coronavirus/en/ [Accessed 27 Apr 2020].

10 Brand SPC, Aziza R, Kombe IK, et al. Forecasting the scale of the COVID-19 epidemic in Kenya. MedRxiv 2020.

11 Worldometer. Coronavirus update (live): 2,489,956 cases and 170,552 deaths from COVID-19 virus pandemic, 2020. Available: https://www.worldometers.info/coronavirus/ [Accessed $21 \mathrm{Apr}$ 2020].

12 Ferguson NM, Laydon D, Nedjati-Gilani G, et al. Impact of nonpharmaceutical interventions (NPIs) to reduce COVID- 19 mortality and healthcare demand, 2020. Available: https://www.imperial.ac.uk/ media/imperial-college/medicine/sph/ide/gida-fellowships/ImperialCollege-COVID19-NPI-modelling-16-03-2020.pdf [Accessed 23 Mar 2020].

13 Read J, Bridgen J, Cummings D, et al. Novel coronavirus 2019$\mathrm{nCoV}$ : early estimation of epidemiological parameters and epidemic predictions. medRxiv 2020

14 Danon L, Brooks-Pollock E, Bailey M, et al. A spatial model of CoVID-19 transmission in England and Wales: early spread and peak timing. MedRxiv 2020.

15 Arenas A, Cota W, Gomez-Gardenes J, et al. A mathematical model for the spatiotemporal epidemic spreading of COVID19. MedRxiv 2020.

16 Mizumoto K, Kagaya K, Zarebski A, et al. Estimating the asymptomatic proportion of coronavirus disease 2019 (COVID-19) cases on board the diamond Princess cruise SHIP, Yokohama, Japan, 2020. Eurosurveillance 2020;25:2000180.

17 Nishiura H, Kobayashi T, Miyama T, et al. Estimation of the asymptomatic ratio of novel coronavirus infections (COVID-19). MedRxiv 2020

18 Ganyani T, Kremer C, Chen D, et al. Estimating the generation interval for COVID-19 based on symptom onset data. MedRxiv 2020.

19 Al-Tawfiq JA. Asymptomatic coronavirus infection: MERS-CoV and SARS-CoV-2 (COVID-19). Travel Med Infect Dis 2020:101608.

20 Oliver $\mathrm{N}$, Letouzé $\mathrm{E}$, Sterly $\mathrm{H}$, et al. Mobile phone data and COVID-19: missing an opportunity? 2020. arXiv 2003;12347.

21 European Centre for Disease Prevention and Control. Geographic distribution of COVID-19 cases worldwide. Eur cent dis Prev control, 2020. Available: https://www.ecdc.europa.eu/en/publications-data/ download-todays-data-geographic-distribution-covid-19-casesworldwide [Accessed 2 Apr 2020]

22 Coronavirus Disease (COVID-19) - Statistics and Research Our World in Data, 2020. Available: https://ourworldindata.org/ coronavirus [Accessed 21 Apr 2020].

23 Day M. Covid-19: four fifths of cases are asymptomatic, China figures indicate. BMJ 2020;369:m1375

24 Wang $\mathrm{H}$, Wang Z, Dong $\mathrm{Y}$, et al. Phase-adjusted estimation of the number of coronavirus disease 2019 cases in Wuhan, China. Cell Discov 2020;6:1-8.

25 D'Errico J. fminsearchbnd, fminsearchcon - File Exchange MATLAB Central, 2020. Available: https://www.mathworks.com/ matlabcentral/fileexchange/8277-fminsearchbnd-fminsearchcon [Accessed 21 Apr 2020].

26 Africa CDC - COVID-19 Daily Updates. Afr CDC, 2020. Available: https://africacdc.org/covid-19/ [Accessed 27 Apr 2020].

27 Murray CJ, Team IC-19 health service utilization forecasting,. Forecasting COVID-19 impact on hospital bed-days, ICU-days, ventilator-days and deaths by US state in the next 4 months. MedRxiv 2020

28 Heesterbeek JAP, Dietz K. The concept of R o in epidemic theory. Stat Neerl 1996;50:89-110.

29 Yang W, Zhang W, Kargbo D, et al. Transmission network of the 2014-2015 Ebola epidemic in Sierra Leone. J R Soc Interface 2015;12:20150536.

30 Zhou F, Yu T, Du R, et al. Clinical course and risk factors for mortality of adult inpatients with COVID-19 in Wuhan, China: a retrospective cohort study. Lancet 2020;395:1054-62.

30 Grasselli G, Zangrillo A, Zanella A. Baseline characteristics and outcomes of 1591 patients infected with SARS-CoV-2 admitted to ICUs of the Lombardy region, Italy. JAMA 2020.

32 GBD results tool |GHDx, 2020. Available: http://ghdx.healthdata.org/ gbd-results-tool [Accessed 28 Apr 2020].

33 van Zandvoort $\mathrm{K}$, Jarvis $\mathrm{Cl}$, Pearson $\mathrm{CAB}$, et al. Response strategies for COVID-19 epidemics in African settings: a mathematical modelling study. MedRxiv 2020.

34 Pearson CA, Schalkwyk CV, Foss AM, et al. Projected early spread of COVID-19 in Africa. MedRxiv 2020.

35 United Nations Economic Commission for Africa. COVID-19 in Africa: protecting lives and economies, 2020. Available: https:// www.uneca.org/publications/covid-19-africa-protecting-lives-andeconomies [Accessed 27 Apr 2020].

36 The World Bank. World development indicators | DataBank, 2020. Available: https://databank.worldbank.org/source/worlddevelopment-indicators [Accessed 28 Apr 2020]

37 Wang J, Tang K, Feng K, et al. High temperature and high humidity reduce the transmission of COVID-19. Rochester, NY: Social Science Research Network, 2020. https://doi.org/10.2139/ssrn.3551767

38 Sajadi MM, Habibzadeh P V, et al. Temperature, humidity and latitude analysis to predict potential spread and seasonality for COVID-19. Rochester, NY: Social Science Research Network, 2020. https://doi.org/10.2139/ssrn.3550308

39 Prem K, Cook AR, Jit M. Projecting social contact matrices in 152 countries using contact surveys and demographic data. PLoS Comput Biol 2017;13:e1005697.

40 Dong W, Guan T, Lepri B, et al. PocketCare. proC ACM interact mob wearable ubiquitous Technol, 2019. Available: https://dl.acm.org/doi/ abs/10.1145/3328912 [Accessed 28 Mar 2020].

41 Mahase E. Covid-19: who and South Korea investigate reconfirmed cases. BMJ 2020;369:m1498.

42 Walker P, Whittaker C, Watson O, et al. Report 12: the global impact of COVID-19 and strategies for mitigation and suppression 2020.

43 Current world population by country. Population data for every country as of 2020, 2020. Available: https://countrymeters.info/en [Accessed 2 Apr 2020].

44 Mclntosh K. Coronavirus disease 2019 (COVID-19). UpToDate Hirsch MS Bloom, 2020: 5.

45 Verity R, Okell LC, Dorigatti I, et al. Estimates of the severity of coronavirus disease 2019: a model-based analysis. Lancet Infect Dis 2020. doi:10.1016/S1473-3099(20)30243-7. [Epub ahead of print: 30 Mar 2020]. 


\title{
Correction: The relatively young and rural population may limit the spread and severity of COVID-19 in Africa: a modelling study
}

Diop BZ, Ngom M, Pougué Biyong C, et al. The relatively young and rural population may limit the spread and severity of COVID-19 in Africa: a modelling study. BMJ Global Health 2020;5: e002699.

This article has been corrected since it published online to include the below funding information:

Binta Zahra Diop's PhD is funded by the Center for the Study of African Economies and the Global Challenges Research Fund. Marieme Ngom's work was supported by the U.S. Department of Energy, Office of Science, under Contract DE-AC02-06CH11357. Clémence Pougué Biyong's PhD is funded by the French Ministry of Higher Education and Ecole Normale Supérieure of Rennes. John N. Pougué Biyong's PhD is funded by the UK Engineering and Physical Sciences Research Council (EPSRC).

\begin{abstract}
Open access This is an open access article distributed in accordance with the Creative Commons Attribution Non Commercial (CC BY-NC 4.0) license, which permits others to distribute, remix, adapt, build upon this work non-commercially, and license their derivative works on different terms, provided the original work is properly cited, appropriate credit is given, any changes made indicated, and the use is non-commercial. See: http://creativecommons.org/licenses/by-nc/4.0/.

(C) Author(s) (or their employer(s)) 2020. Re-use permitted under CC BY-NC. No commercial re-use. See rights and permissions. Published by BMJ.
\end{abstract}

BMJ Global Health 2020;5:e002699corr1. doi:10.1136/bmjgh-2020-002699corr1 